Research Article

\title{
COMPARISON OF THE PRINTING AREAS FOR COMMONLY USED FONT TYPES: EXAMPLE OF GREEN INFORMATION
}

\author{
Emrah AYDEMIR ${ }^{1 *}$
}

\begin{abstract}
Some of the fonts used in the computer systems are designed to facilitate readability on the computer screen while others are designed to use both readability and print space economically. However, computer users do not have any idea which of the most commonly used fonts are more economical. In the present study, the printing area of the 10 commonly used fonts were examined with image processing methods and compared among each other. It is seen that the font which uses the least print area among Century Schoolbook, Courier New, Georgia, Times New Roman, Arial, Comic Sans MS, Tahoma, Verdana, Cambria, Calibri fonts is Courier New whereas the type that uses the least print area is Times New Roman. It was found that Comic Sans MS and Verdana used almost twice as much printing area as the font Courier New font. With this study, it is thought that computer users will be more careful and more conscious about the font they use for printing.
\end{abstract}

Key words: Font Types, Printing Area, Image Processing, Green IT

\section{Introduction}

As a result of various social, economic and environmental factors, it can be said that less paper is used recently. Specifically, users prefer e-mail, projector, document scanning, double-sided printing, single-spaced text, recycled paper, printing multiple pages per page, smaller font size, margin reduction, toner / ink saving mode, colorless and paper-free printing solutions [1]. Users and companies may also seek for such simple solutions that don't require investment.

Font designers put great efforts to choose features such as the type and size of the font to make the reader's reading experience more enjoyable and more comfortable. The typography of the text undoubtedly influences the reader's reading and comprehension performance $[2,3]$. In addition, the font type and font size are also effective on reading and comprehension $[4,5]$. Indirectly, text type can be said to affect the printing area used while printing on type paper. Türk Telekom has developed a font type with $25 \%$ less ink / toner for its use [6]. In this study, the widely used font types were compared regarding the use of the print area. Thus, it is aimed to increase both individual and institutional awareness about green IT.

\section{Green Information Technologies}

Reducing the use of environmentally harmful materials and chemicals in information and communication technology products or the use of recyclable products can be considered as green information. Technologies aiming to minimize the environmental impact of design, production and use of tools such as computers, monitors, printers, network and communication systems known as green IT [7]. In green IT, respect for nature and the efficient use of products are essential [8]. It also contributes to environmental

\footnotetext{
1 Department of Computer Engineering, Kirsehir Ahi Evran University, Kırşehir, TURKEY, (emrah.aydemir@ahievran.edu.tr) (D)https://orcid.org/0000-0002-8380-7891
} 
sustainability through equipment that uses energy more effectively. Energy efficiency is provided not only by hardware but also by green software [9]. Especially virtualization technology is one of the best examples of this condition [10]. However, the awareness of individuals and institutions about green IT is very low [11]. The UK is the first country to focus on green IT strategies and policies [12]. The ultimate aim of green computing is to reduce operational costs and increase the efficiency of the IT infrastructure [13]. Individual and corporate users of information technologies can choose and apply the solution they want to use to reduce costs.

\section{Commonly Used Font Types}

Effective reading, fast reading, charm and general preference font types were examined and eight fonts were found to be widely used [14]. Hashim and Majid [15] used these fonts and the Calibri font in the readability of web texts. However, it has been concluded that fonts do not have an effect on web readability. These fonts are listed below.

\section{Comic Sans MS}

2. Verdana

3. Tahoma

4. Arial

5. Georgia

6. Century Schoolbook

7. Times New Roman

8. Courier New

9. Calibri

Times New Roman font type is designed for both legible and print economy. The Georgia font type is similar to the Times New Roman font type, but is particularly legible on the computer screen. The Century Schoolbook font type is also designed to be more legible, especially in books, and is widely used in school books [14].

Thesis manuscripts of the Institute of Science and Technology belonging to 208 state and private universities in Turkey examined the font types given in Table 1 below. Some universities have allowed their students to use more than one font. Some of the universities have been excluded from the evaluation due to their being a vocational school, not being an institute of science or lack of a thesis guide, resulting in 68 universities in total.

Table 1. Font Type and Number of Universities Using

\begin{tabular}{lll}
\hline Font Type & Number of Universities & Rate $(\%)$ \\
\hline Arial & 22 & 9,13 \\
Bitstream-Charter & 1 & 0,41 \\
Calibri & 9 & 3,73 \\
Cambria & 4 & 1,66 \\
Helvetica & 1 & 0,41 \\
Tahoma & 2 & 0,83 \\
Times New Roman & 132 & 54,77 \\
Verdana & 2 & 0,83 \\
There is no Institue or thesis writing guide & 68 & 28,22 \\
\hline Grand Total & 241 & 100 \\
\hline
\end{tabular}

The majority of the universities (54.77\%) prefer the Times New Roman font type. Then Arial font type was preferred with 9.13\%. Other font types are used in very few universities. With Helvetica, the Bitstream- 
Charter font type is used only at a university. These font types are not installed in the Windows 10 version and in Microsoft Office 2016 by default. Therefore, these font types were excluded from the study. Cambria was added to nine font types and 10 font types were examined.

The 10 font types specified here are printed on 12-point A4 paper. Figure 1 below shows the $400 \%$ zoom of the "S" character. Only solid black is used, and each character is under the corresponding font. Figure 1 shows that some font types are thicker and more dominant when carefully examined. However, in some font types, thinner and lesser points are used. Such properties are effective in the use of the print area. Montrucchio and Ferrero [16] also found that in order to reduce the use of toner in these studies, these characters were able to place white spots in dense places and save about $40 \%$ of toner. Similar results were observed in different studies [17, 18]. Another method of saving toner is to illuminate some areas of characters in print. For example, only the color values of the internal pixels are exposed from the pixel groups of the same color. Thus, outlines are unaffected [19]. It is another method to make the inner and edge pixels independent [20] or to just open some parts of the image [21].

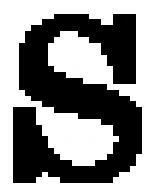

Century Schoolbook

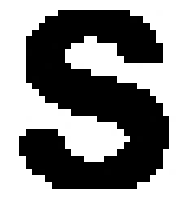

Arial

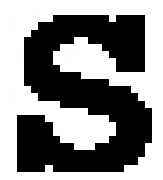

Courier New

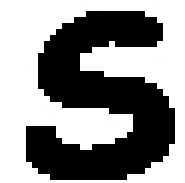

Comic Sans MS

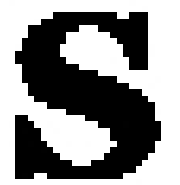

Georgia

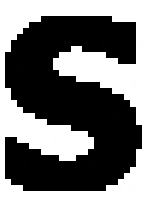

Tahoma

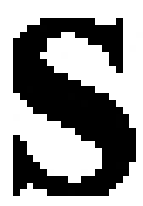

Times New Roman

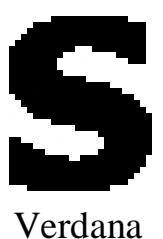

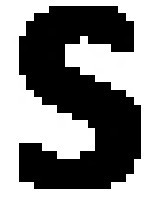

Calibri

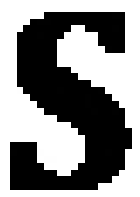

Cambria

Figure 1. A Letter of Commonly Used Font Types (400\% Zoomed)

\section{Method}

Font type and font size are important for less ink / toner consumption [22]. For this reason, with 10 commonly used font types in the study, 10 verses of the National Anthem were written in Word file to fit on one page. Then the output from this word file is saved as an image file with jpg extension. With the help of $\mathrm{C}$ \# programming language, image files with jpg extension have been converted to Bitmap file type. Thus, red, green and blue values of each pixel will be accessible. These values consist of values between $0-255$. The pixels of the image files created here are either full black or full white. By counting the black pixels and white pixels, the necessary analyzes were made and the ratio of the blacks was extracted. Thus, the use of printing area has been determined. Pixel numbers are calculated by the following equations. 


$$
T_{S}=\sum_{i=0}^{y} \sum_{j=0}^{d} s
$$

$T_{s}=$ Total black pixel count

$y=$ Total number of horizontal pixels in paper

$g=$ Total number of vertical pixels in paper

$s=$ Black pixel

$$
T_{b}=\sum_{i=0}^{y} \sum_{j=0}^{d} b
$$

$T_{b}=$ Total white pixel count

$b=$ White pixel

$$
T_{p}=T_{s}+T_{b}
$$

$T_{p}=$ Total pixel count

The number of white pixels is calculated by counting the white pixels by scanning all pixels horizontally and vertically. The number of black pixels is calculated similarly and the sum of the two gives the total number of pixels. As a result of the ratio of these values with the following equation 4, the printing area utilization ratio is calculated.

$\varphi=$ Black pixel ratio

$$
\varphi=\frac{T_{s}}{T_{s}+T_{b}}
$$

\section{Results}

The calculated number of black pixels and white pixel numbers for each font is given in Table 2 below. In this case, the font with the least use of the print area was Courier New with 3.55\%. The Times New Roman font is $4.94 \%$ followed by the least printable area.

Table 2. Print Area Usage Ratios of Font Types

\begin{tabular}{lllll}
\hline Font Types & $\begin{array}{l}\text { Total white pixel } \\
\text { count }\end{array}$ & $\begin{array}{l}\text { Total black pixel } \\
\text { count }\end{array}$ & Total & Black Ratio(\%) \\
\hline Comic Sans MS & 3619078 & 249628 & 3868706 & 6,452493 \\
Verdana & 3619623 & 249083 & 3868706 & 6,438406 \\
Tahoma & 3622015 & 246691 & 3868706 & 6,376577 \\
Arial & 3633961 & 234745 & 3868706 & 6,067791 \\
Georgia & 3644581 & 224125 & 3868706 & 5,793281 \\
Cambria & 3668706 & 200000 & 3868706 & 5,169687 \\
Century Schoolbook & 3672691 & 196015 & 3868706 & 5,066681 \\
Times New Roman & 3679757 & 188949 & 3868706 & 4,884036 \\
Calibri & 3684153 & 184553 & 3868706 & 4,770406 \\
Courier New & 3731099 & 137607 & 3868706 & 3,556926 \\
\hline
\end{tabular}


Comic Sans MS and Verdana font types have been found to have the most printing area fonts. It would be correct to say that these fonts use approximately twice as much printing space as the Courier New font type. There is a $0.1 \%$ difference between Times New Roman and Calibri font type.

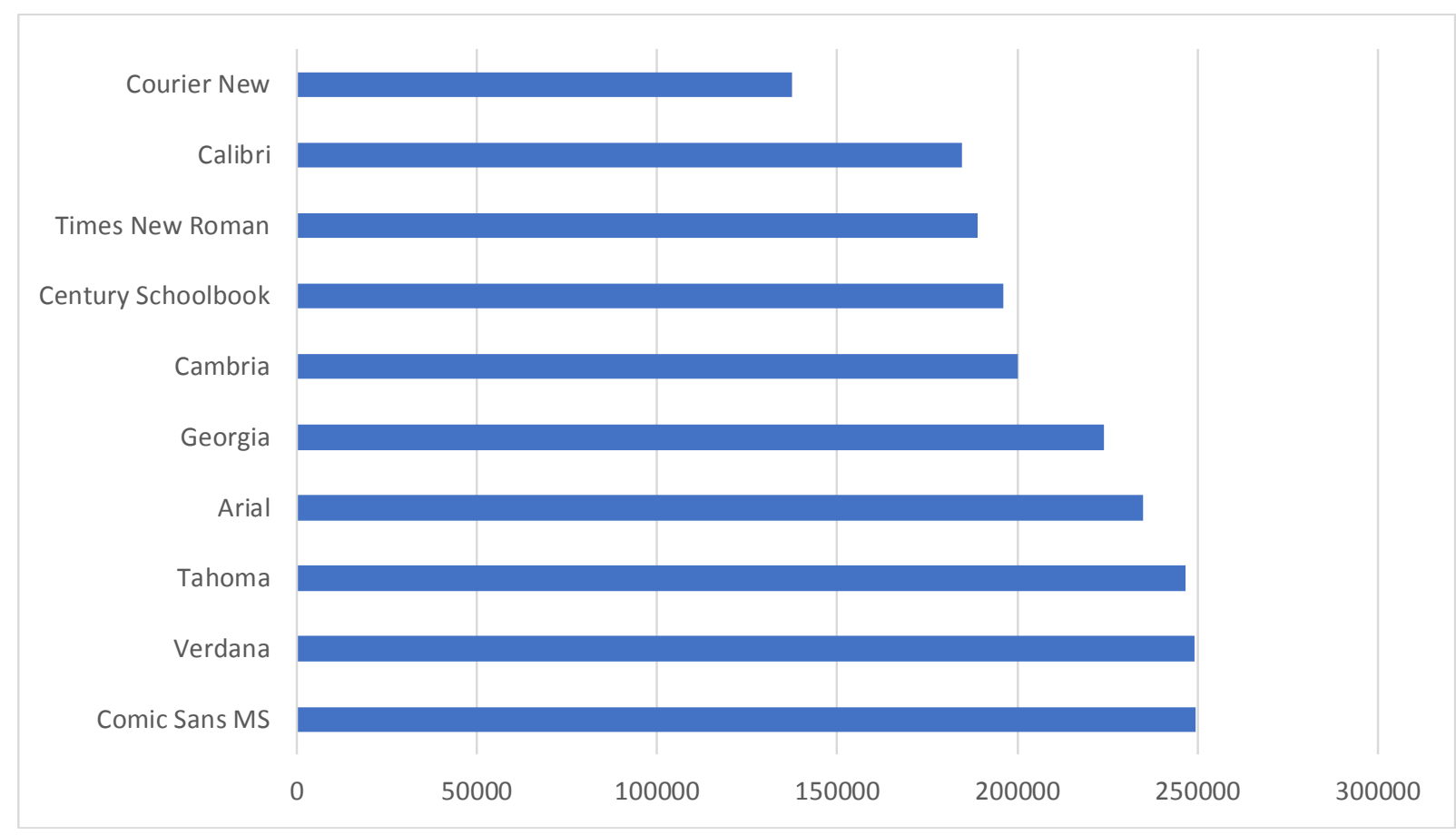

Figure 2. Black Pixel Numbers by Font Types

Black pixel numbers according to font types are shown in Figure 2 and there is very little difference between Comic Sans MS, Verdana and Tahoma but this difference is very high for Times New Roman and Courier New.

\section{Discussion and Conclusion}

Due to the fact that computers are indispensable devices of today, much of the information is obtained through these tools. In some cases, the information must be transferred from the computer to the paper. Even though this situation is reduced by different solutions, some users think that paper transfer is still necessary [23]. In this study, it was investigated which common fonts would be appropriate to use less toner or ink in case of paper printing. It has been seen that the Courier New font uses the most printing area of the 10 commonly used fonts. It would not be correct to say that reading from the computer screen is more disadvantaged than reading paper [24]. Therefore, of course, not printing is the right solution. However, selecting the font types that use less toner / ink when printing is required will be the most suitable option for greener printing. Milošević et al. [25] also produced similar results. The font generated by the font called eco-font was found to use $39 \%$ less ink than other fonts. It was seen that these two different fonts could be parsed by the users but not the problem. The Regulation on the Procedures and Principles to be Applied in the Official Correspondences [26] covering all public institutions and organizations states that the electronic documents will use Times New Roman or Arial as the font. However, the Times New Roman font uses approximately 10\% less print space than the Arial font. This means that $10 \%$ toner savings will be achieved if the Times New Roman font type is selected and applied in all public institutions. It is good to see that the Times New Roman font type is mostly used in the thesis writing guidelines of the Institute of Science. Considering this situation, other 
institutions and organizations will undoubtedly have many different benefits. Some of these are less damage to nature, less paper consumption, less toner consumption, less electricity. Particularly while efforts are being made for a sustainable ecosystem [29] on the one hand, ignoring such issues will be in contradiction in itself. Unhelkar [27] also refers to a number of users to reduce the environmental impact of information technologies in their daily life, such as turning off the monitor, minimizing printing operations or using recycled paper. It would be right to say that there is almost no difference between Times New Roman and Calibri. This difference can be ignored and the two font types can be considered equal in terms of the print area. Furthermore, in future studies, both fonts that use less print space and methods that can hide data in various ways can be used [28].

\section{References}

[1]. Werner, K., Rothenberg, S., \& Miller, J. (2012). Drivers of greener print choices: an exploratory study of print consumer environmentalism, A Research Monograph of the Printng Industry Center at RIT. https://scholarworks.rit.edu/books/101.

[2]. Ralekar, C., Saha, P., Gandhi, T. K., \& Chaudhury, S. (2018). Effect of Devanagari Font Type in Reading Comprehension: An Eye Tracking Study. In International Conference on Intelligent Human Computer Interaction. Springer, Cham, 136-147.

[3]. Kumar, R., Malik, A., Singh, S., Kumar, B., \& Chand, S. (2016, April). A space based reversible high capacity text steganography scheme using font type and style. In 2016 International Conference on Computing, Communication and Automation (ICCCA) (pp. 10901094). IEEE.

[4]. Kim, H., \& Park, S. H. (2012). What are Legible Korean Font Sizes within In-Vehicle Information Systems?. Journal of the Ergonomics Society of Korea, 31(2), 397-406.

[5]. Kim, S., Lee, K. E., \& Lee, H. W. (2013). The Effect of Hangul Font on Reading Speed in the Computer Environment. Journal of the Ergonomics Society of Korea, 32 (5), 449-457.

[6]. Haberturk, (2019). A first in the world from Türk Telekom, Online Available: https://www.haberturk.com.

[7]. Laudon, K. C., \& Laudon, J. P. (2015). Management information systems: Managing digital business. Ankara, Turkey: Nobel Publisher.

[8]. Damar, M., \& Goksen, Y. (2018). User and Institution Oriented Energy Management System with Green IT Approach. Dokuz Eylul University Faculty of Engineering Science and Engineering Journal, 20 (58), 259-274.

[9]. Kern, E., Dick, M., Johann, T., \& Naumann, S. (2011). Green software and green it: An end users perspective. In Information Technologies in Environmental Engineering (pp. 199-211). Springer, Berlin, Heidelberg.

[10]. Cetin, H. and Akgun, A. (2015). A Comparison of Virtualized and Traditional Systems in the Context of Green Information Technologies. Journal of Alanya Faculty of Business, 7 (2), 131-142.

[11]. Goksen, Y., Damar, M., and Dogan, O. (2016). Green Computing: A Case Study In A State Organization And Policy Recommendations. Ege Academic Review, 16 (4), 673-686.

[12]. Chai-Arayalert, S., \& Nakata, K. (2011, August). The evolution of green ICT practice: UK higher education institutions case study. In Proceedings of the 2011 IEEE/ACM International Conference on Green Computing and Communications (pp. 220-225). IEEE Computer Society.

[13]. Agrawal, N., \& Agarwal, K. N. (2012). Current trends in green ict. JoAAG, 7(1), 71-85.

[14]. Bernard, M., Lida, B., Riley, S., Hackler, T. and Janzen, K. (2002). A comparison of popular online fonts: Which size and type is best. Usability news, 4 (1).

[15]. Hashim, A. A., \& Majid, M. A. (2015). Effects of video display terminal resolutions to the legibility of text on a web page. International Journal of Software Engineering and Computer Systems, 1(1), 131-157.

[16]. Montrucchio, B., \& Ferrero, R. (2016). Toner savings based on quasi-random sequences and 
a perceptual study for green printing. IEEE Transactions on Image Processing, 25(6), 26352646.

[17]. Shu, J. (1995). Error diffusion with ink reduction for high quality and high resolution ink jet printing. In Proceedings. IEEE International Conference on Image Processing, 3(1), 121-124.

[18]. Guo, J. M. (2006). A complete printer model in error-diffused halftone images. In Proceedings. IEEE International Conference Image Process, 1529-1532.

[19]. Davidson, M. L., \& Hawkins, B. C. (2001). U.S. Patent No. 6,266, 153. Washington, DC: U.S. Patent and Trademark Office.

[20]. Rombola, G., \& Foster, T. J. (2009). U.S. Patent No. 7,602,510. Washington, DC: U.S. Patent and Trademark Office.

[21]. Ray, E. T. (2013). U.S. Patent No. 8,467,105. Washington, DC: U.S. Patent and Trademark Office.

[22]. Možina, K., Medved, T., Rat, B., \& Bračko, S. (2010). Influence of light on typographic and colorimetric properties of ink jet prints. Journal of Imaging Science and Technology, 54(6), 60403-1-60403-8.

[23]. Josephson, S. (2008). Keeping your readers' eyes on the screen: an eye-tracking study comparing sans serif and serif typefaces. Visual communication quarterly, 15(1-2), 67-79.

[24]. Duran, E., \& Alevli, O. (2014). The effect of reading on screen on comprehension of 8th grade students. Literacy Education Research, 2 (1), 1-11.

[25]. Milošević, R., Nedeljković, U., Banjanin, B., Novaković, D., \& Kašiković, N. (2016). The analysis of ink jet printed eco-font efficiency. Journal of Graphic Engineering and Design, $7(1), 1-13$.

[26]. The Regulation on the Procedures and Principles to be Applied in the Official Correspondences, (2015). T. C. Official Newspaper, Number: 29255, 2 February 2015.

[27]. Unhelkar, B. (2011). Green IT: The next five years. IT Professional, 13(2), 56-59.

[28]. Tuncer, T., \& Sönmez, Y. (2017). Block based data hiding method for images. European Journal of Technique, 7(2), 85-95.

[29]. Mesbah, L. A. (2014). Ecosystem Services for a Sustainable Energy Policy in Bosnia and Herzegovina. Balkan Journal of Electrical and Computer Engineering, 2(3), 108-112. 